\title{
UMA NOVA CĀMARA COLETORA PARA ARMADILHA CDC-MINIATURA
}

\author{
Almério de Castro Gomes* \\ Ernesto Xavier Rabello* \\ Délsio Natal*
}

GOMES, A. de C. et al. Uma nova câmara coletora para armadilha CDC-miniatura. Rev. Saúde públ., S. Paulo, 19:190-1, 1985.

RESUMO: Foram feitas modificações no modelo original da armadilha CDCminiatura, visando uma maior proteção do material coletado contra-chuvas. Essas alterações garantem o uso do aparalho em áreas de alta pluviosidade.

UNITERMOS: Armadilha CDC-miniatura. Diptera, captura.

\section{INTRODUÇÃO}

A armadilha CDC-miniatura é do tipo automática e luminosa, tendo uso generalizado em pesquisas entomológicas. Foi desenvolvida por Sudia e Chamberlain² (1962), possuindo em seu modelo original (Fig. A) a vantagem de ser desmontável, leve e com câmara coletora dobrável, tendo motor alimentado por 4 pilhas comuns de 1,5 vcc, tipo AA. Essas características, associadas a seu rendimento, fazem desse equipamento um dos mais práticos, sendo largamente utilizado em capturas de dípteros de interesse médico, principalmente culicídeos (Service ${ }^{1}$, 1977).

Apesar de as características do modelo serem vantajosas, observou-se durante pesquisas que vêm sendo desenvolvidas pela equipe de entomologia, do Departamento de Epidemiologia da Faculdade de Saúde Pública, em áreas do Estado de São Paulo, que a câmara coletora ficava frequientemente molhada por ocasião de fortes chuvas, o que provocava danos ao material entomológico coletado.

Devido a esse problema, julgou-se necessário fazer algumas alterações visando adaptar melhor a armadilha às cir- cunstâncias climáticas das áreas de trabalho. Assim sendo, a câmara coletora original foi substituída por outra de tela metálica (60 malhas por $\mathrm{cm}^{2}$ ) de latão. A nova câmara possui diâmetro igual ao corpo do aparelho, sendo ligada a esse por meio de manga de tecido fino de algodão branco. Além disso, o fundo da câmara (em chapa de latão) é removível, facilitando a retirada do material (Fig. B). A fina malha utilizada na câmara coletora impede a fuga de pequenos dipteros como flebotomíneos e simulídeos. Além dessas modificações, foi adaptado um tubo de PVC de $15 \mathrm{~cm}$ de diâmetro por $30 \mathrm{~cm}$ de comprimento, o qual envolve a câmara coletora e a manga, estando o mesmo preso ao suporte da tampa protetora de chuva (Fig. C). Dessa maneira, fica garantida a preservação do material coletado, mesmo em períodos de intensas chuvas.

\section{AGRADECIMENTO}

Ao Daniel Marucci do Departamento de Epidemiologia da Faculdade de Saúde Pública da USP, pela elaboração das fotografias.

\footnotetext{
- Do Departamento de Epidemiologia da Faculdade de Saúde Pública da Universidade de São

Paulo - Av. Dr. Arnaldo, 715 - 01255 - São Paulo, SP - Brasil.
} 
GOMES, A. de C. et al. Uma nova câmara coletora para armadilha CDC-miniatura. Rev. Saúde públ., S. Paulo, 19:190-1, 1985.

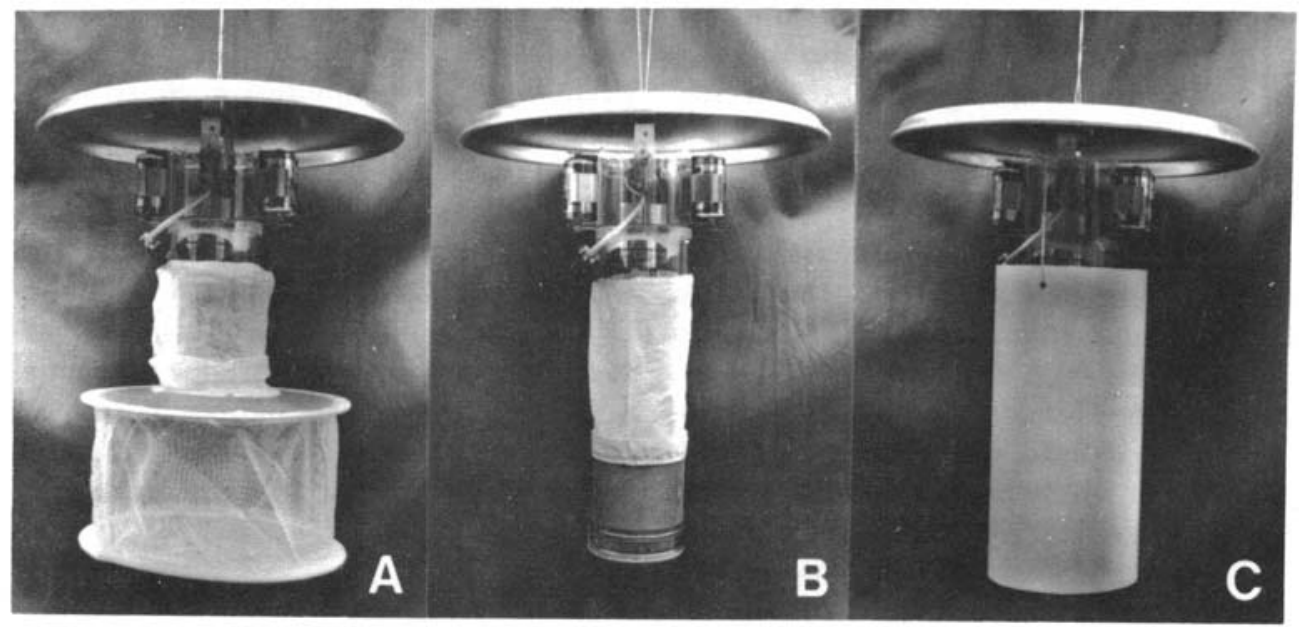
Figura - Modificaçōes da armadilha CuC-miniatura. visando proteção da câmara coletora con-
tra chuva. A modelo original; B - com câmara coletora modificada; C - pro-
tegida com tubo PVC.

GOMES, A. de C. et al. [A new collecting chamber for the CDC - miniature trap]. Rev. Saúde públ., S. Paulo, $19: 190-1,1985$.

ABSTRACT: Some modifications of the light CDC-miniature trap with a view to providing greater protection of the collected material against rain are presented. These modification make the use of this trap possible even in regions of heavy rainfall.

UNITERMS: Light CDC-miniature trap. Diptera, collection.

\section{REFERENCIAS BIBLIOGRÁFICAS}

1. SERVICE, M.W. A critical review of procedures for sampling populations of adult mosquitoes. Bull ent. Res., 67: 343-82, 1977.
2. SUDIA, W.D. \& CHAMBERLAIN, R.W. Battery operated light trap, an improved model. Mosquito News, 22:126-9, 1962.

Recebido para publicação em 26/02/1985 Aprovado para publicação em 21/03/1985 